\title{
Population growth, energy use, and environmental impact: Comparing the Canadian and Swedish records on $\mathrm{CO}_{2}$ emissions
}

\author{
Don $\operatorname{Kerr}^{1}$
}

\begin{abstract}
There are many similarities between Canada and Sweden, as both are relatively affluent northern nations with diverse modern economies. Both have witnessed demographic growth and climbing affluence, with predominantly export-oriented economies. Yet in terms of their respective records on greenhouse gas emissions, there is a stark contrast between the two. Sweden is often considered a world leader in reducing emissions, whereas Canada has been widely criticized for its failure to meet international commitments. The current paper attempts to delineate some of the factors responsible for the observed differences between the two countries. It examines trends in environmental impact ( $\mathrm{CO}_{2}$ levels) by applying a modified and updated version of Ehrlich's IPAT equation. The crux of the matter in comparing the two countries is Canada's substantial population growth and heavy demand for energy (29th among 30 countries in the OECD on our measure of energy intensity) whereas Sweden has managed to move away from fossil fuels in driving its economic activity.
\end{abstract}

Keywords: population, environment, energy, $\mathrm{CO}_{2}$ emissions, greenhouse gases.

\section{Résumé}

Il y a beaucoup de similitudes entre le Canada et la Suède; ce sont deux pays nordiques relativement fortunés avec des économies modernes diversifiées. Tous les deux ont connu une croissance démographique et une plus grande richesse, leurs économies étant principalement axées sur l'exportation. Pourtant, en ce qui concerne leurs dossiers respectifs sur l'émission de gaz à effet de serre, il y a un net contraste entre les deux. La Suède est souvent considérée comme une chef de file mondial dans la réduction des émissions et le Canada fait l'objet d'une vaste critique pour ne pas respecter ses engagements internationaux. Cet article cherche à définir quelques facteurs responsables des différences observées entre les deux pays. Il examine les tendances relatives à l'impact environnemental (niveaux de $\mathrm{CO}_{2}$ ) au moyen d'une version modifiée et mise à jour de « l'équation IPAT » d'Ehrlich. Le nœud du problème dans la comparaison des deux pays est que l'importante croissance démographique du Canada et sa forte dépendance l'énergie (le pays arrive en $29^{\mathrm{e}}$ place sur 30 pays de l'OCDE en ce qui concerne l'intensité de l'énergie), alors que la Suède a réussi à diriger son activité économique en délaissant les combustibles fossiles.

Mots-clés : population, environnement, énergie, émissions de $\mathrm{CO}_{2}$ gaz à effet de serre.

1. Don Kerr, Department of Sociology, King's University College, University of Western Ontario, 266 Epworth Avenue, London, Ontario N6A 2M3. E-mail: dkerr@uwo.ca. 
Kerr: Population growth, energy use, and environmental impact

\section{Introduction}

According to the UN's Human Development Index, which allows for international comparisons in terms of population health and social welfare, both Canada and Sweden are doing very well, ranking 8th and 9th, respectively, across over 170 countries (UN 2011a). Using data on life expectancy, literacy, education, and standard of living, this index summarizes the relative success of countries in terms of promoting the social welfare of their populations. At the same time, the two countries differ dramatically in terms of their respective records on greenhouse gases (GHGs). On a per-capita basis, Canada produces about 20 tons of greenhouse gases per person, relative to less than 7 tons in Sweden-expressed as $\mathrm{CO}_{2}$ equivalent (Environment Canada 2011; SEPA 2011). There are relatively few nations in the world that produce as much GHG relative to population size as Canada, whereas Sweden has been very successful in developing a modern economy without the same sort of carbon footprint.

There are many similarities between Canada and Sweden, as both are northern nations, with diverse modern economies, a relatively high standard of living, and long democratic traditions. Both have witnessed substantial economic growth over recent decades, with export-oriented economies featuring a highly skilled labor force, excellent internal and external communications, a modern distribution system, and a similar industry/service breakdown in terms of employment (service sector comprises 76 of the Canadian workplace relative to 71 per cent of persons employed in Sweden). Yet in terms of their respective records on GHG emissions, there is a stark contrast between the two, as Sweden is often considered a world leader in reducing emissions, whereas Canada has been widely criticized for its failure to meet international commitments (Simpson et al. 2007).

The current paper attempts to delineate some of the factors responsible for the observed differences between the two countries, while also providing an international context. More specifically, how has Canada and Sweden performed relative to the OECD, and what are some of the factors responsible for Sweden's relative success and Canada's comparative failure? As the bulk of GHG are $\mathrm{CO}_{2}$ emissions resulting from energy use and the burning of fossil fuels (i.e., about 80 per cent in both countries), the current paper limits its focus primarily to $\mathrm{CO}_{2}$ emissions. Quality information is available from the International Energy Association (IEA) on $\mathrm{CO}_{2}$ emissions and energy use, supplemented by demographic and economic data as available from the UN and OECD. As a matter of introduction, on a per capita basis, Canada ranked 27th across the OECD in 2009 in terms of the carbon footprint, whereas Sweden has managed to produce less than any other wealthy nation, 3rd in the OECD behind only the developing economies of Mexico and Turkey (Figure 1). In addition, the disparity between the two countries has only been increasing over recent years, with $\mathrm{CO}_{2}$ emissions up by roughly 20 per cent in Canada over the 1990-2009 period, whereas Sweden experienced a reduction of fully -21 per cent.

In terms of methodology, this paper examines trends in environmental impact ( $\mathrm{CO}_{2}$ levels) by applying a modified and updated version of what is widely known among demographers as Ehrlich's IPAT equation (Ehrlich and Holdren 1971). Borrowing from demography and industrial ecology, IPAT is an acronym used to emphasize the utility of investigating environmental impact (I) as a direct function of population change $(\mathrm{P})$ and affluence $(\mathrm{A})$ as well as technological change $(\mathrm{T})$. As population (P) is often viewed as a fundamental driver of environmental impact (i.e., the larger the population, the greater the impact, all else held constant), it is useful to begin with differences across nations in terms of demographic growth. As climbing affluence (A) is associated with increased consumption and energy use, it is also useful to examine the variation that exists across countries in terms of level 


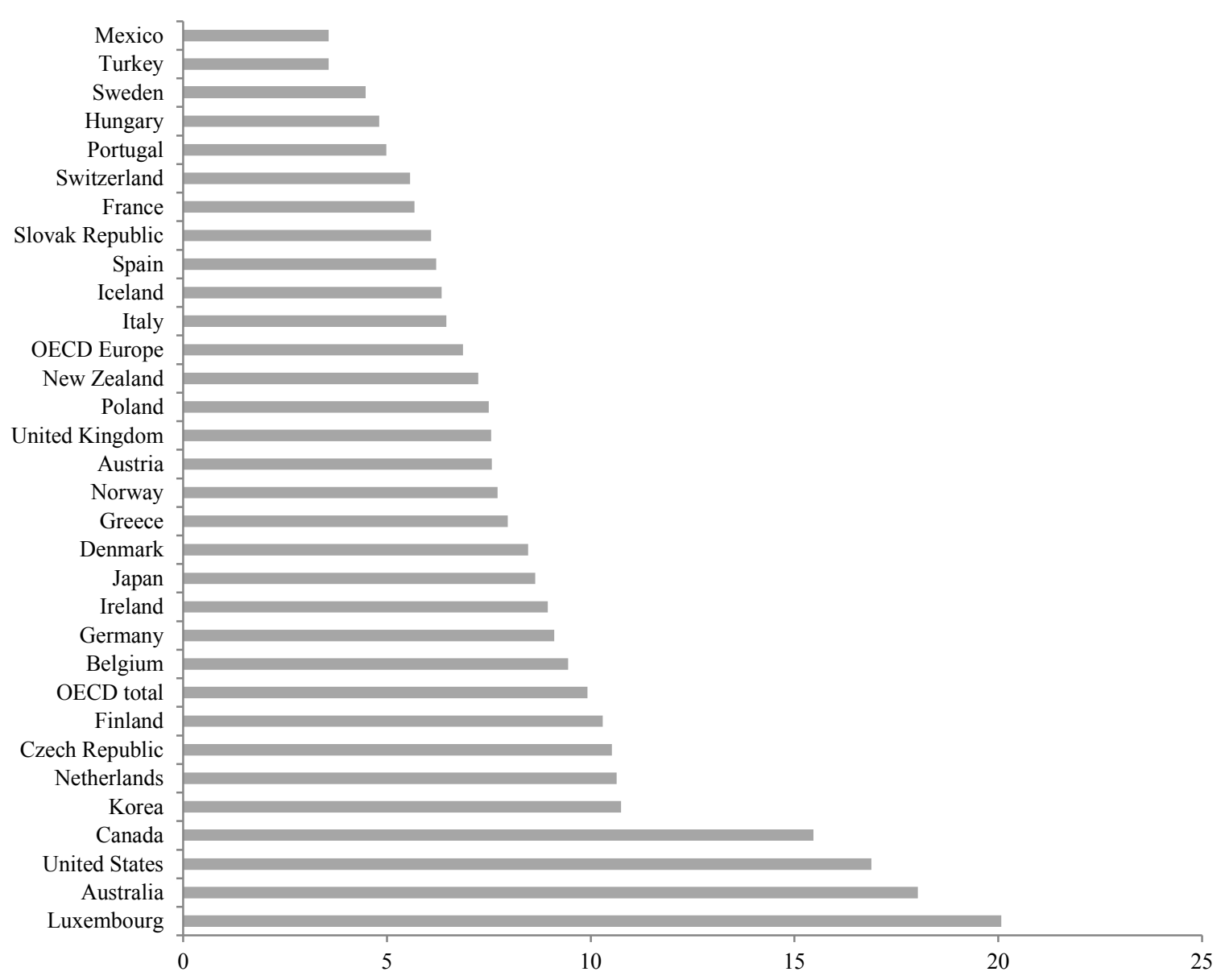

Figure 1. Carbon emissions per capita across OECD countries, 2009. Source: IEA 2011 and UN 2011a.

of affluence, and how this has been evolving over recent years. Since technology $(T)$ is often viewed as particularly fundamental in understanding environmental impact (I), this paper borrows from a growing literature of energy-related carbon emission studies that extends the technology component in IPAT in the decomposition of $\mathrm{CO}_{2}$ emissions (Kaya 1990; Hamilton and Turton 2002; IPCC 1996; Karakaya and Ozcag 2005; Kerr and Mellon 2012).

Technology potentially contributes to increased environmental impact (as an example, by shifting to more $\mathrm{CO}_{2}$-intensive fossil fuels) while also holding the potential for decoupling $\mathrm{CO}_{2}$ levels from economic growth (for example, by shifting away from such fuels to other non-conventional energy sources). The current study attempts to highlight this point by systematically comparing Canada with Sweden, placing their apparent successes and failures into a broader context within the OECD. Societies differ in terms of their reliance on fossil fuels and the types of fossil fuels used, not to mention differences in the energy intensity of economic activity, efforts toward conservation, and the efficiencies that exist in energy conversion technologies. While on the surface there appear to be many similarities between Canada and Sweden, the divergent trends observed in the two countries are quite striking. As documented in the current paper, Sweden's record on reducing $\mathrm{CO}_{2}$ emissions is among the strongest in the OECD, while Canada's record continues to be among the poorest. 
Kerr: Population growth, energy use, and environmental impact

\section{The IPAT Identity}

In the early 1970s, Ehrlich and Holdren $(1971,1972)$ formulated the IPAT equation with the intent of refuting any argument that "population size," in and of itself, was a minor factor in explaining environmental change. Consistent with Ehrlich and Holdren's neo-Malthusian worldview, rapid population growth was considered as one of the "most unyielding of all environmental pressures" (1971: 150). The IPAT equation, in its simplicity, was proposed as a starting point for investigating the impact of human populations on the environment. As the global population was growing at an unprecedented pace, an understanding of the environmental impact would have to begin with current population size and pace of population growth.

These interrelationships have been summarized in terms of the IPAT equation or impact equation, as follows:

$$
\text { Impact }(\mathrm{I})=\text { Population }(\mathrm{P}) \times \text { Affluence }(\mathrm{A}) \times \text { Technology }(\mathrm{T})
$$

Impact (I) refers to the amount of a particular kind of environmental degradation; population (P) refers to the size of a population; affluence (A) is typically measured in terms of income (or GDP) per capita; and technology $(\mathrm{T})$ is meant to capture the environmentally damaging properties of a particular technique. Working with this IPAT equation, the argument is that an increase in population $(\mathrm{P})$ would lead to a proportional increase in environmental impact (I), if in fact there were no change in the other components (and likewise, this is also true of both affluence and technology). While this model has been criticized as being somewhat of an oversimplification, its primary utility was to highlight the centrality of demography in discussions of environmental problems. Although the rate of global population growth has slowed since the 1960s, there remains considerable variance across nation-states, from the particularly low growth associated with many low-fertility/lowimmigration nations in Europe to the more sustained growth characteristic of North America and other parts of the world.

Despite the potential for more complex models, IPAT has been used by researchers as a useful framework for investigating interactions of population, economic growth, and technological change. While extensive debate continues as to the relative importance or "weight" of each term, there is a wide consensus that each of the terms definitely belongs in the equation. In treating this model as linear, with the effects of the different terms being proportional, the Intergovernmental Panel on Climate Change (IPCC 2000) has used a revision of this identity to decompose change in anthropogenic GHG emissions by major world region. As a simple, robust model for descriptive work, the IPAT model has been applied as an identity, such that for a specific nation-state, $\mathrm{CO}_{2}$ emissions can be expressed as a direct function of population size (P), GDP/Population (A), and $\mathrm{CO}_{2}$ emissions/ GDP (T):

$$
\mathrm{CO}_{2} \text { emissions }=\text { Population } \times \frac{\mathrm{GDP}}{\text { Population }} \times \underline{\mathrm{CO}_{2}} \frac{\text { emissions }}{\mathrm{GDP}}
$$

While GDP/Population does not fully capture the social dimension of environmental impact, it does reflect the simple fact that there is substantial variation in affluence across societies-even within the OECD. While not all nations within the OECD are affluent (consider Mexico and Turkey, for example), most have witnessed substantial economic growth over recent years. While populations have grown steadily throughout the 20th century, affluence (or economic activity) has grown at an even more rapid pace. Affluence is often considered a critical determinant of environmental degrada- 
tion, because high rates of consumption tend to be associated with a larger ecological footprints and rapid rates of resource use and waste production (Rees 1992). In general, increased affluence-with everything else held constant—implies a greater demand for energy and higher $\mathrm{CO}_{2}$ emissions. In terms of relative affluence, both Canada and Sweden have witnessed substantial growth in terms of GDP per capita, although the manner in which this translates into increased impact appears to have differed significantly in comparing the two nations.

In our comparison of Canada with Sweden, we seek to apply and extend this equation, while also making further comparisons more broadly with other OECD countries. This involves borrowing from a growing literature of energy-related carbon emission studies that have been used to decompose differences in $\mathrm{CO}_{2}$ emissions across nation-states (Kayo 1990; Hamilton and Turton 2002; IPCC 1996; Karakaya and Ozcag 2005). This literature seeks to not only demonstrate the centrality of population growth (P) and affluence (A) to environmental impact, but to decompose, in particular, the role of technology $(\mathrm{T})$ in determining energy use patterns and environmental impact.

\section{Technology and environmental impact}

The technology term $(\mathrm{T})$ incorporates some sort of combination of capital, labor, energy, materials, and information in the production and consumption of specific goods or services. The role of technology can be considered as particularly complex, as it is often at the heart of many environmental difficulties (as for example, the $\mathrm{CO}_{2}$ emissions resulting from burning dirty coal), while also holding the promise of potential solutions (as for example, the development of "clean" or "renewable" energy). While Ehrlich and other environmentalists warned against a blind faith in technological fixes for serious environmental problems, many social scientists pragmatically view technological variables as being potentially easier to manage than human behavior (Commoner et al. 1971; Simon 1981; Chertow 2001). A comparison of Sweden with Canada on this front does demonstrate the importance of this factor in particular, as two societies of comparable affluence have had dramatically differing impact on the environment in terms of level and growth in $\mathrm{CO}_{2}$ emissions.

There are various ways in which technology $(\mathrm{T})$ can lower environmental impact, including the switch away from high-polluting fossil fuels to other energy resources. Fossil fuels (oil, natural gas, and coal) continue to be fundamental in meeting the energy needs of most societies, such that their specific mix of these fuels can potentially have a dramatic effect. Coal is obviously the dirtiest, most noxious fuel to burn, with the shift toward other sources holding considerable promise in reducing emissions. Natural gas is clearly preferable to coal or oil, when possible, as it generates fewer pollutants, particulates, and $\mathrm{CO}_{2}$ for every billion joules of energy produced, releasing $14 \mathrm{~kg}$ of $\mathrm{CO}_{2}$ relative to $20 \mathrm{~kg}$ and $24 \mathrm{~kg}$ for oil and coal, respectively (Harper and Fletcher 2011). The precise mix (or carbon intensity) of fossil fuels has an important place to play in explaining the progress (or lack thereof) of specific OECD countries. The environmental costs associated with the extraction, mining, refining, transportation, consumption, and substantial polluting byproducts vary in an important manner by fuel type and across OECD countries.

Electricity is often thought of as a less polluting alternative, although of course, this depends upon how the electricity is generated. Clapp (2002) refers to the "distancing" of environmental impact, both geographically and mentally, as consumers of energy sometimes do not recognize the environmental impact of energy generation at source. Many consumers use electricity in their homes without realizing that it is commonly generated through the combustion of fossil fuels. Many societies rely heavily upon coal in the generation of electricity, as is the situation in the United States, where 45 per cent of total electricity comes from burning coal. In Canada, fully 16.5 per cent of elec- 
Kerr: Population growth, energy use, and environmental impact

tricity supply is generated from coal, with an additional 5.2 per cent generated from natural gas and 1.9 per cent from petroleum (NRC 2010). Consequently, the total supply of energy is greater than the total energy directly consumed, i.e., energy is lost in conversion from fossil fuels into electricity. Typically, across societies, $\mathrm{CO}_{2}$ emissions are produced both directly in the burning of fossil fuels, and sometimes, to a greater or lesser extent, indirectly in the conversion of fossil fuels into electricity, with the level of efficiency involved in this conversion inversely associated with overall emissions. Typically, the lower the conversion efficiency, the greater the demand for fossil fuels in meeting the demand for electricity (by both households and industry), and subsequently, the greater the overall emissions associated with this process.

In meeting its energy needs, Canada has clearly invested in infrastructures to produce, process, and use coal, oil, and natural gas — which, in turn, has made it more difficult to shift to alternative (less polluting) energy technologies. For example, the use of oil in Canada has grown almost exponentially, due to the simple fact that it remains relatively cheap and is fundamental to the transportation sector, in the movement of persons and goods. While the North American economy is heavily reliant on fossil fuels, this situation is not true to the same extent in other OECD countries - and in parts of Western Europe and Scandinavia in particular (Boyd 2001). As will be demonstrated in the current paper, Sweden, in particular, has been very successful in reducing its dependence on fossil fuels, with a much lower proportion of its current energy supply coming from this source. Just as the carbon intensity of fossil fuel usage varies across societies, so does the fossil fuel intensity" of economic activity. As an example, France has managed to reduce its dependency on fossil fuel imports through considerable investment in nuclear energy (albeit with all its associated risks and hazards). In Sweden, a variety of energy sources has come to replace fossil fuels, with major development of alternative energy sources, such as hydroelectricity as well as nuclear and, to a lesser extent, geothermal, wind and solar energy.

In the North American context, a wide set of historical factors, including an early abundance of conventional energy resources, has left a legacy of powerful tax biases and subsidies that have encouraged the use of fossil fuels while discouraging longer-term investment in alternative energy technology. In addition - for a wide variety of reasons, including the economic structure of Canada's economy - the energy intensity of economic activity is higher here than elsewhere. With all of these considerations, Hamilton and Turton (2002) set out to extend the aforementioned IPAT decomposition, to move beyond the carbon intensity of different economies $\left(\mathrm{CO}_{2}\right.$ emissions/GDP) as an indicator of the impact of technology. Using detailed information on levels and type of energy use from the International Energy Association (IEA), it is possible to further extend the IPAT model, such that the carbon intensity in economic activity (the T component in Equation 2) can be broken down into four further terms (see Equation 3 below).

In the following equation, the acronym FOSS represents total fossil fuel consumption, TPES represents total primary energy supply (prior to any conversion of energy resources, if applicable), and TFC represents total final energy consumption. In addition to the impact of population $(\mathrm{P})$ and affluence (GDP/Population), we can move on to identify, for each OECD country, four distinct technology effects:

$$
\begin{aligned}
\mathrm{CO}_{2} \text { emissions }= & \text { Population } \times \frac{\mathrm{GDP}}{\text { Population }} \times\left[\mathrm{CO}_{2} / \mathrm{FOSS}\right] \\
& \times[\text { FOSS } / \text { TPES }] \times[\mathrm{TPES} / \mathrm{TFC}] \times[\mathrm{TFC} / \mathrm{GDP}]
\end{aligned}
$$


As portrayed by Equation 3, it is possible to delineate a (i) carbon intensity effect $\left[\mathrm{CO}_{2} / \mathrm{FOSS}\right]$; (ii) fossil fuel intensity effect [FOSS/TPES]; (iii) conversion efficiency effect [TPES/TFC]; and (iv) energy intensity effect [TFC/GDP]. With regard to the first term, the carbon intensity effect is merely the ratio of $\mathrm{CO}_{2}$ emissions relative to total fossil fuel combustion [FOSS]. This term would be at its highest in societies that burn the dirtiest of fossil fuels, including low-grade, high-carbon content, sulfur-rich coal. With the second technology term, the fossil fuel intensity effect indicates the proportion of total primary energy supply [TPES] that is obtained from fossil fuels [FOSS]. This term is obviously highest in societies that have failed to develop alternative sources of energy, whether they be nuclear, hydro, geothermal, wind, or solar. With the third technology term, the conversion efficiency effect, represents the extent to which energy resources are used to create energy in another form (as for example, coal is used in the generation of electricity). As the ratio of total primary energy supply [TPES] relative to total final consumption of energy [TFC], it varies according to conversion efficiency and the fuel mix or type of primary energy supply used. The fourth technology term, or the "energy intensity effect of economic activity" is merely total final energy consumption [TFC] relative to the total size of a given economy [GDP]. This reflects both investment in energy efficiency (where Canada's record is not particularly strong) as well as the nature of economic activity and economic structure (industrial, commercial, service, resource-based, agricultural, etc.).

Hamilton and Turton (2002) have applied this model to the 1980-1997 data from the International Energy Association (IEA), comparing a limited number of European and North American countries. Karakaya and Ozcag (2005) have enacted a similar exercise across several nation-states in Central Asia. We shall again use this IPAT decomposition to further update this research through to 2009, yet this time with a specific emphasis on Canada and Sweden, all relative to 28 other countries within the OECD. We shall begin with a brief discussion of Canada's and Sweden's respective circumstances in terms of population and economic growth over recent years, prior to considering the technology components in Equation 3, all relative to what is happening elsewhere in the OECD.

\section{Population growth and environmental impact}

Canada's population growth has been relatively robust over recent decades, achieving +21.6 per cent over the period 1990-2009 (Figure 2). In fact, Canada is among the most rapidly growing OECD countries, with only a few others experiencing faster growth-particularly the high-fertility countries of Turkey and Mexico, as well as other countries also noted as being particularly open to immigration, including Australia, New Zealand, the United States, and, most recently, Iceland and Ireland. On the other hand, Sweden has not experienced nearly as much demographic pressure, with its population up by 8.8 per cent over this same period (i.e., by well under half the per cent increase documented for Canada). In this regard, Sweden's demographic situation is similar to elsewhere in Europe, whereas Canada fits closer the broader North American pattern. Europe has had a much longer history of low fertility, which has resulted in substantial population aging, lower rates of natural increase, and more modest demographic growth relative to elsewhere in the OECD.

While both Sweden and Canada have had comparable fertility rates (TFRs) during the 1990s and 2000s (between 1.5 and 1.8 births per female), Sweden's history of below-replacement fertility goes back much further than Canada. For example, Sweden never experienced the substantial upturn in fertility that characterized the baby boom era in North America. As a result, Sweden has an older age structure than Canada, with currently almost 19 per cent of its population over the age of 65, relative to only about 13 per cent in Canada. In North America, the baby-boom cohorts-born during the 1950s and early 1960s_ - are currently middle-aged, and for this simple reason, Canada continues to 
Kerr: Population growth, energy use, and environmental impact

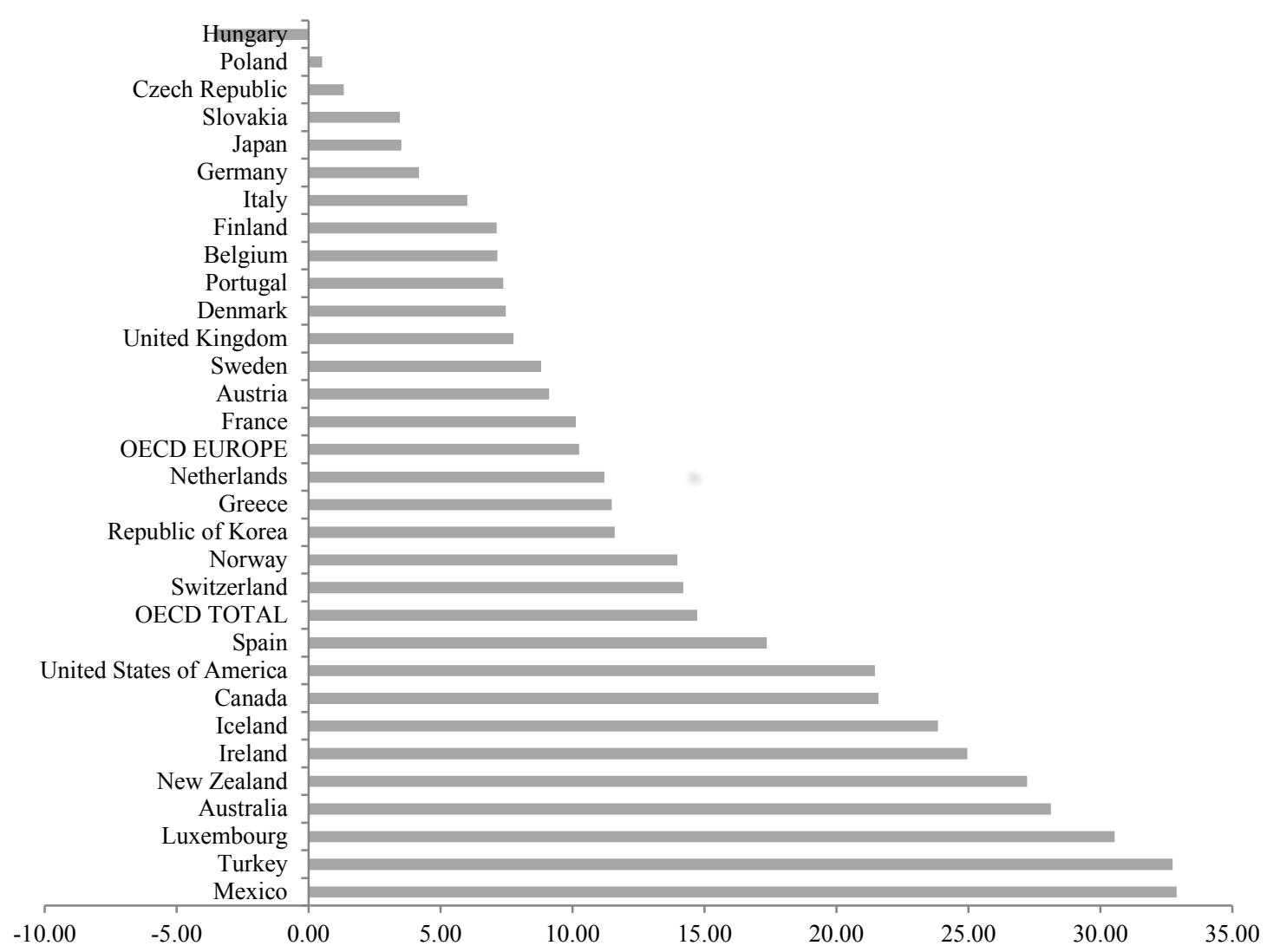

Figure 2. Population growth across OECD Countries, 1990-2009.

Source: UN Department of Economic and Social Affairs, Population Division 2011, author's calculations.

have a substantially lower proportion of its population over the age of 65 . Older populations tend to grow more slowly, as is the case with Sweden, which has an age distribution that produces more deaths and fewer births relative to populations with younger age structures.

Canada has more in common with the broader North American pattern, with continued growth through positive natural increase (more births than deaths) supplemented with relatively high immigration targets. Sweden's rate of natural increase has already dropped on a couple of occasions into negative territory (more deaths than births), something that is not anticipated for Canada for at least an additional 15-20 years (Statistics Canada 2010). While Sweden admits on a per-capita basis more immigrants than most European countries, it does not welcome nearly as many immigrants as Canada, either overall or relative to the total size of its population. While most of Sweden's growth is currently through net international migration, its lower immigration targets (relative to North America) are supplemented by modest growth through natural increase.

As Canada has experienced considerable demographic growth without shifting away from its heavy reliance on fossil fuels, overall $\mathrm{CO}_{2}$ emissions have climbed rapidly. As aforementioned, Canadian $\mathrm{CO}_{2}$ emissions are up by +20 per cent over the 1990-2009 period, whereas Sweden actually succeeded in reducing emissions by -21 per cent. The question that could be asked in this context is: "To what extent do the Canadian and Swedish records differ as a result of their very different rates of population growth?" Consistent with the logic of the IPAT model, we might assume that Canada's growth in $\mathrm{CO}_{2}$ emissions is at least partially the byproduct of relatively rapid population growth, just as Sweden's preferred outcome on $\mathrm{CO}_{2}$ emissions occurred in the context of much more modest demographic growth. 
Assuming no departure from observed trends in terms of all the components in the IPAT, with the "exception of population," how might Canada's record on $\mathrm{CO}_{2}$ emissions have differed with a population increase similar to that of Europe or Scandinavia? Similarly, how might Sweden's record have differed had it experienced demographic growth of the order of countries like Canada or the United States? Figure 3 briefly addresses this issue with a relatively simple exercise: (i) it contrasts the observed per cent climb in emissions for Canada with what this country might have hypothetically experienced with demographic growth comparable to Sweden's (i.e., a population growth of 8.8 per cent rather than the observed population growth of 21.6 per cent); and (ii) we do the converse, con-

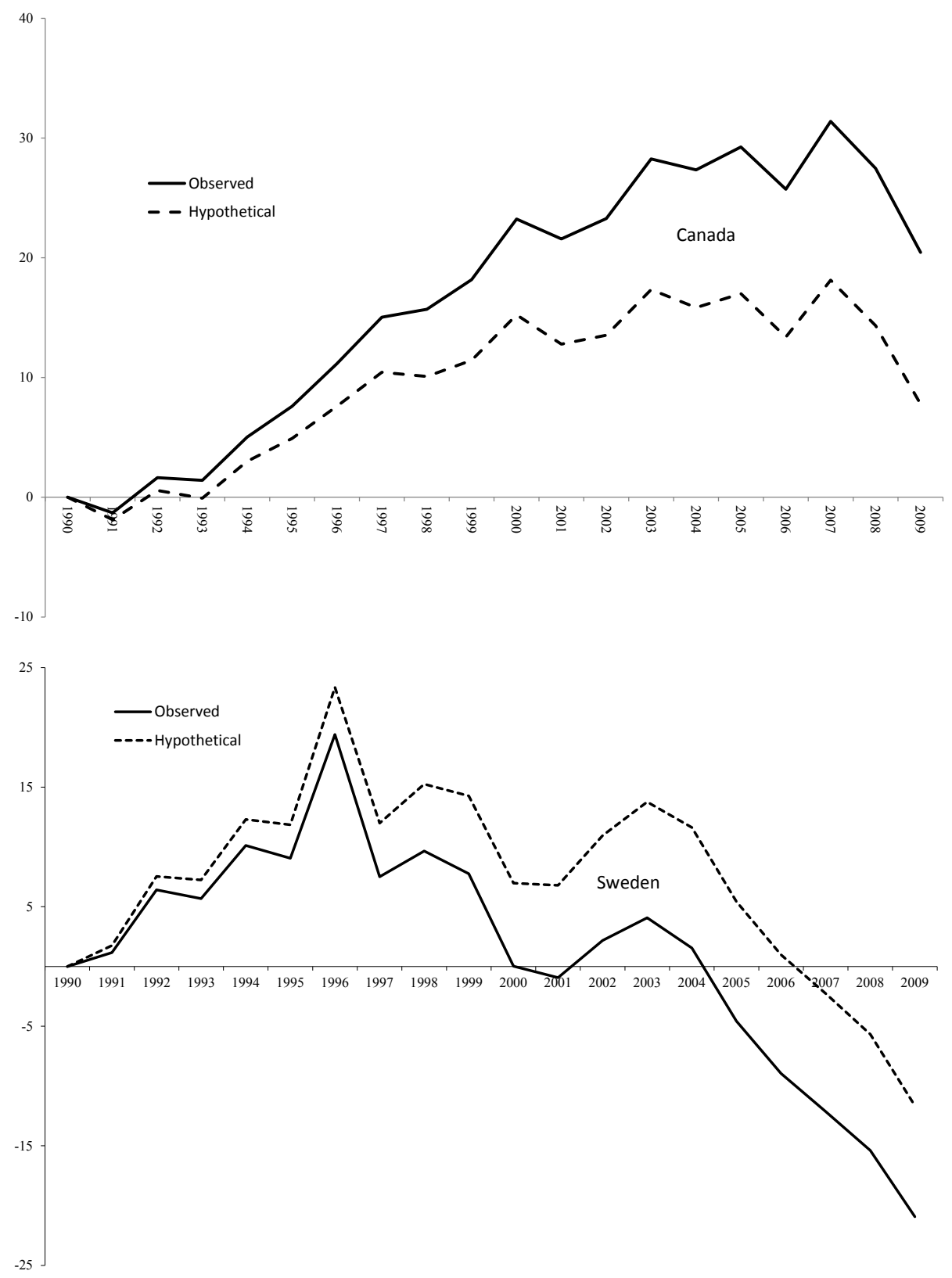

Figure 3. Growth in $\mathrm{CO}_{2}$ emissions in Canada and Sweden, 1990-2009, with observed and hypothetical rates of population growth.

Source: Author's calculations. 
Kerr: Population growth, energy use, and environmental impact

trasting the observed per cent decline in emissions for Sweden with what that country might have witnessed with demographic growth of the order of Canada.

By assuming no departure from the observed trends in terms of affluence (A) or technology $(\mathrm{T})$, our simulation implicitly assumes that these components have roughly proportional effects which are largely independent of population growth. This directly implies that the time-series on GDP per capita and $\mathrm{CO}_{2}$ emissions per unit GDP would have remained unchanged, with the only difference relating to the rate of population growth. To the extent that this is a reasonable assumption, what is clear is that Sweden's success in reducing emissions would have been cut in half - that is, a -11.6 per cent decline rather than the observed -20.9 per cent. Similarly, the estimated climb in emissions for Canada under this slower growth scenario would be more than cut in half, from the observed +20.4 per cent to about +7.8 per cent.

\section{$\mathrm{CO}_{2}$ emissions and affluence}

While Canada's population growth has clearly outpaced Sweden's, the same is not true of our second IPAT component, i.e., affluence (A). While much of the OECD has recently experienced economic stagnation and contraction - starting with the financial crisis of 2008- the longer time-series (1990-2009) suggests a period of substantial growth, with all OECD economies larger in 2009 than they were a few decades earlier. ${ }^{2}$ While climbing affluence (and associated consumption) is logically relevant in explaining why emissions have increased in most countries, there are obviously confounding factors that obscure the nature of the relationship. After adjusting all figures to constant US dollars, our indicator of affluence, i.e., GDP per capita, was up by +27.9 per cent in Canada (notwithstanding the fiscal crisis of 2008), by +29.8 per cent for the OECD average, and even further, by +31.1 per cent for the Swedes for the 1990-2009 period. In other words, our indicator of "affluence" for Sweden climbed at a slightly more rapid pace than has Canada's, without this being translated into the same sort of proportional increase in $\mathrm{CO}_{2}$ emissions. Both the Canadian and Swedish economies grew at about the middle of the pack among OECD countries, yet in this context, the two economies differed quite a bit in terms of environmental impact.

Affluence (A) is considered a critical determinant of environmental degradation, because high rates of consumption tend to be associated with larger ecological footprints, a greater demand for energy, and rapid rates of resource use and waste production. Although the IPAT indicator "GDP/ population" is an imperfect measure of affluence (A), it is used here to highlight the possible economic pressures that contribute to increased $\mathrm{CO}_{2}$ emissions. As a general rule, in following the logic of the IPAT equation, the greater the level of affluence (or GDP per capita) in a given society, the greater the environmental impact-with everything held constant. Across the OECD, there is considerable variation in GDP per capita, from a high of almost $\$ 70,000$ in Luxembourg to a low of just over $\$ 10,000$ in Turkey (Figure 4). In comparing Sweden with Canada, clearly both countries rank relatively high, with Canada ranking slightly higher than Sweden (9th and 12th overall) Yet, as afore-

2. In providing some sense as to the impact of this economic downturn, our indicator of affluence (GDP per capita, in constant dollars) declined by roughly -4 per cent in Canada over the 2007-2009 period and -7 per cent in Sweden. This decline in GDP per capita actually occurred across 27 of the 30 OECD countries listed here, with a reduction of about -5 per cent in GDP per capita for the OECD overall. At the same time, overall $\mathrm{CO}_{2}$ emissions, after rising +17.4 per cent over the 1990-2007 period, fell by roughly -8.5 per cent across the OECD over the 2007-2009 period. In this context, it is far from certain as to how much of this decline was due to economic recession and a subsequent reduction in the demand for energy and how much was the result of successful initiatives to reduce GHG emissions more generally. 


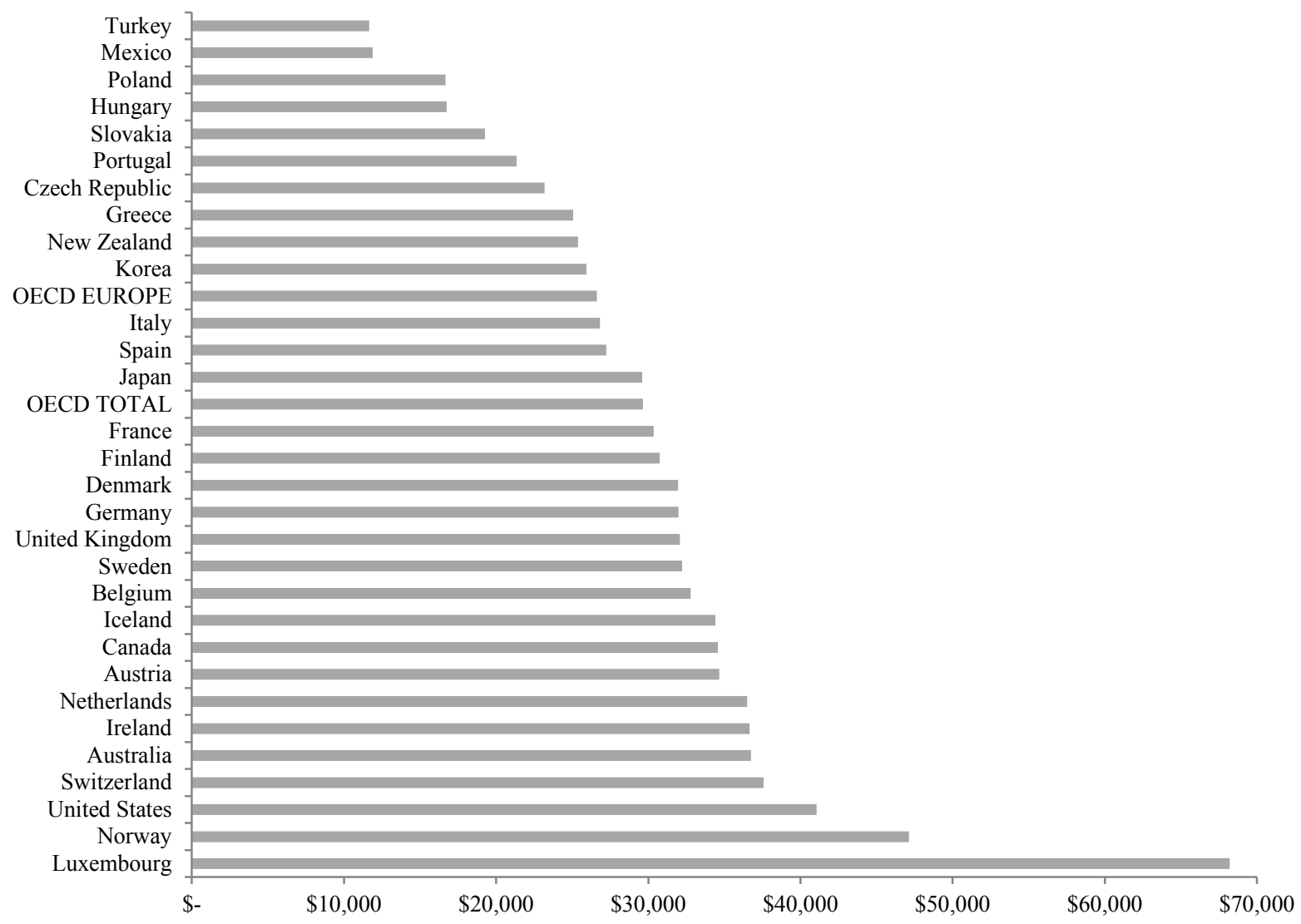

Figure 4. GDP per capita across OECD countries, 2009.

Source: UN Department of Economic and Social Affairs, Population Division 2011a; OECD 2011.

mentioned, the situation of Sweden is particularly unique, i.e., it has managed to achieve this relatively high level of affluence, by all international standards, while also maintaining a surprisingly low carbon footprint. Even further, without considering in detail how this wealth is shared or distributed within these two OECD countries, on a general level Sweden has experienced economic growth in a context of lower income inequality relative to both Canada as well as a majority of OECD countries.

As previously demonstrated (in Figure 1), the OECD's wealthiest nation, Luxembourg, actually has the highest level of carbon emissions on a per capita basis, while the OECD's poorest countries (Turkey and Mexico) actually have the lowest carbon footprints. Yet while affluence is typically associated with greater emissions, there are clearly some rather interesting exceptions to this general rule. For example, Norway, which is second only to Luxembourg in terms of GDP per capita, reports only about one-third of its $\mathrm{CO}_{2}$ emissions per capita (7.71 metric tons of $\mathrm{CO}_{2}$ emissions per capita, compared to 20.07 metric tons). As aforementioned, Sweden produced in 2009 less than one-third of Canada's $\mathrm{CO}_{2}$ emissions per capita (4.48 metric tons per capita, compared to 15.46 metric tons). Across the OECD, only two countries produce lower emissions on a per-capita basis than Sweden (Mexico and Turkey), yet both are particularly poor by OECD standards.

The OECD (2002) has used the term decoupling to refer to breaking the link between environmental bads" and "economic goods." In other words, while most affluent nations have relatively high carbon footprints, a few have managed to "decouple" somewhat their prosperity from this form of environmental impact. Typically, while population, economic growth, and environmental impact tend 


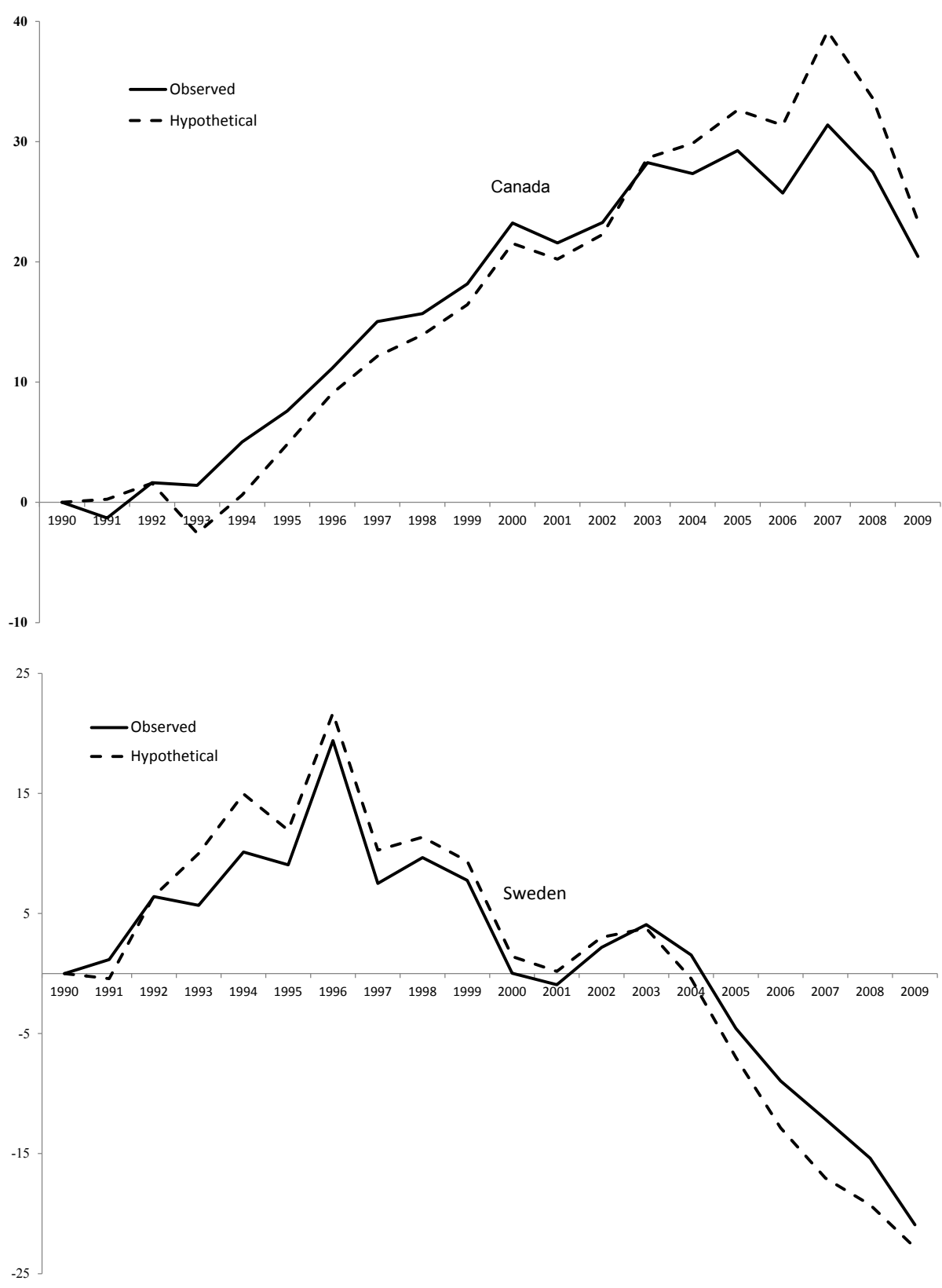

Figure 5. Growth in $\mathrm{CO}_{2}$ emissions in Canada and Sweden, 1990-2009, with observed and hypothetical rates in GDP per capita.

Source: Author's calculations.

to increase together, Sweden and a few other OECD countries have managed to remain relatively prosperous while at least partially "decoupling" economic growth from $\mathrm{CO}_{2}$ emissions. On the other hand, Canada's economy remains particularly carbon intensive, with both GDP per capita and total emissions up substantially over the last two decades.

With this in mind, we again repeat the same exercise as reported earlier with population growth, shifting our attention to differences in terms of affluence (A). More specifically, how might Canada's record on $\mathrm{CO}_{2}$ emissions had differed with an increase in GDP per capita comparable to Sweden's 
Table 1. Technology components, OECD countries, rank 2009.

\begin{tabular}{|c|c|c|c|c|c|c|c|c|c|c|}
\hline \multicolumn{2}{|c|}{$\begin{array}{c}\text { Fossil fuel dependency } \\
\text { FOSS/TPES (2009) }\end{array}$} & \multicolumn{3}{|c|}{$\begin{array}{c}\text { Carbon Intensity } \\
\text { CO2/FOSS (2009) } \\
\end{array}$} & \multicolumn{3}{|c|}{$\begin{array}{l}\text { Conversion effect } \\
\text { TPES/TFC (2009) }\end{array}$} & \multicolumn{3}{|c|}{$\begin{array}{l}\text { Energy intensity } \\
\text { TFC/GDP (2009) }\end{array}$} \\
\hline Rank & & $\operatorname{Ran}$ & & & Ranl & & & Ranl & & \\
\hline 1 Iceland & 0.157 & 1 & Norway & 22.46 & 1 & Luxembourg & 1.09 & 1 & U.K. & 66.80 \\
\hline Sweden & 0.327 & 2 & Belgium & 23.92 & 2 & Austria & 1.20 & 2 & Ireland & 70.02 \\
\hline France & 0.510 & 3 & Netherlands & 24.21 & 3 & Ireland & 1.27 & 3 & Switzerland & 70.09 \\
\hline Switzerland & 0.533 & 4 & Iceland & 24.31 & 4 & Portugal & 1.28 & 4 & Greece & 72.52 \\
\hline Finland & 0.540 & 5 & Mexico & 25.74 & 5 & Netherlands & 1.30 & 5 & Spain & 74.25 \\
\hline 6 Norway & 0.588 & 6 & Hungary & 26.11 & 6 & Denmark & 1.31 & 6 & Italy & 77.69 \\
\hline 7 New Zealand & 0.637 & 7 & Italy & 27.03 & 7 & Canada & 1.31 & 7 & Denmark & 80.58 \\
\hline 8 Slovak Rep. & 0.695 & 8 & U.K. & 27.11 & 8 & Italy & 1.31 & 8 & Mexico & 82.61 \\
\hline 9 Austria & 0.702 & 9 & France & 27.11 & 9 & Turkey & 1.33 & 9 & Portugal & 83.00 \\
\hline 10 Belgium & 0.736 & 10 & Canada & 27.35 & 10 & Switzerland & 1.34 & 10 & Japan & 83.70 \\
\hline 11 Hungary & 0.742 & 11 & Korea & 27.54 & 11 & Finland & 1.36 & & OECD EUR & 84.24 \\
\hline 12 Canada & 0.749 & 12 & Spain & 28.04 & 12 & Spain & 1.37 & 11 & France & 84.55 \\
\hline OECD EUR & 0.760 & 13 & Sweden & 28.05 & 13 & New Zealand & 1.39 & 12 & Germany & 84.97 \\
\hline 13 Portugal & 0.780 & 14 & New Zealand & 28.23 & 14 & Hungary & 1.39 & 13 & Norway & 87.16 \\
\hline 14 Germany & 0.795 & 15 & Portugal & 28.26 & 15 & Sweden & 1.42 & 14 & Turkey & 87.37 \\
\hline 15 Czech Rep. & 0.796 & & OECD EUR & 28.32 & & OECD EUR & 1.42 & 15 & Austria & 90.60 \\
\hline 16 Spain & 0.799 & & OECD & 28.37 & 16 & Germany & 1.42 & 16 & Australia & 96.56 \\
\hline 17 Denmark & 0.804 & 16 & Luxembourg & 28.48 & 17 & Norway & 1.42 & 17 & Netherlands & 99.42 \\
\hline OECD & 0.809 & 17 & Austria & 28.52 & 18 & Gree & 1.43 & & OECD & 99.62 \\
\hline 18 Japan & 0.810 & 18 & Slovak Rep. & 28.54 & 19 & Belgium & 1.46 & 18 & Poland & 100.79 \\
\hline 19 Korea & 0.817 & 19 & U.S.A. & 28.55 & 20 & Poland & 1.46 & 19 & Slovak Rep. & 103.15 \\
\hline 20 U.S.A. & 0.841 & 20 & Japan & 28.58 & & OECD & 1.46 & 20 & Czech Rep. & 106.41 \\
\hline 21 U.K. & 0.873 & 21 & Ireland & 28.97 & 21 & U.S.A. & 1.48 & 21 & Hungary & 106.51 \\
\hline 22 Italy & 0.875 & 22 & Turkey & 29.20 & 22 & U.K. & 1.49 & 22 & Sweden & 106.63 \\
\hline 23 Luxembourg & 0.888 & 23 & Switzerland & 29.54 & 23 & Japan & 1.51 & 23 & Luxembourg & 106.84 \\
\hline 24 Mexico & 0.889 & 24 & Germany & 29.63 & 24 & Slovak Rep. & 1.54 & 24 & Belgium & 112.20 \\
\hline 25 Turkey & 0.899 & 25 & Finland & 30.72 & 25 & Korea & 1.55 & 25 & New Zealand & 113.91 \\
\hline 26 Greece & 0.924 & 26 & Denmark & 31.29 & 26 & Mexico & 1.59 & 26 & United States & 115.75 \\
\hline 27 Poland & 0.928 & 27 & Australia & 31.93 & 27 & France & 1.60 & 27 & Korea & 118.80 \\
\hline 28 Netherlands & 0.931 & 28 & Czech Rep. & 32.88 & 28 & Czech Rep. & 1.63 & 28 & Finland & 148.46 \\
\hline 29 Australia & 0.944 & 29 & Poland & 32.88 & 29 & Australia & 1.69 & 29 & Canada & 166.73 \\
\hline 30 Ireland & 0.950 & 30 & Greece & 33.18 & 30 & Iceland & 1.86 & 30 & Iceland & 259.24 \\
\hline
\end{tabular}

Source: Author's calculations, IEA 2011; UN 2011.

(which was slightly greater than Canada's, at 31.1 per cent relative to 27.9 per cent); and vice-versa, how might Sweden's decline in $\mathrm{CO}_{2}$ be modified by a rate of economic growth comparable to Canada's. We again simplify things by making the implicit assumption that the other IPAT components have independent and proportional effects, and that over time, observed trends in population $(\mathrm{P})$ and technology $(\mathrm{T})$ remain unchanged from what was observed. As demonstrated in Figure 5, since our indicator of affluence (A) increased more rapidly in Sweden than Canada, then Canadian emissions would have been even higher under this scenario (up +23.4 per cent rather than the observed increase of +20.4 per cent) — whereas Sweden's success would have been even greater (down by -22.8 per cent rather than the -20.9 per cent as observed). To a certain extent, it would appear that the impact of demographic growth in comparing the two countries has at least been partially offset by differences in economic growth. Yet in terms of the substantial differences that remain, it is necessary to 
Kerr: Population growth, energy use, and environmental impact

turn to other factors beyond affluence and demography — that is, to the third component of IPAT, the technology component $(\mathrm{T})$.

\section{$\mathrm{CO}_{2}$ emissions and technology}

The technology component in IPAT is fundamental to understanding better the current $\mathrm{CO}_{2}$ emissions in both Canada and Sweden. As aforementioned, the technology component can be further delineated into four separate terms, including: (i) a fossil fuel intensity effect, (ii) a carbon intensity effect, (iii) a conversion efficiency effect, and (iv) an energy intensity effect. Prior to considering how these terms have changed over time, for Canada and Sweden separately, Table 1 summarizes how the two countries are currently performing on these four separate terms - again, relative to all other countries within the OECD. Table 1 also provides the rank order of Canada and Sweden on each of these terms across the OECD, which theoretically at least, ranks countries from having the lowest environmental impact (rank 1) through to highest (rank 30). All figures are presented for 2009, while acknowledging that $\mathrm{CO}_{2}$ emissions are down somewhat since 2007, due at least partially to the most recent global recession and economic downturn.

The fossil fuel dependency effect indicates the proportion of total primary energy supply obtained from coal, oil and natural gas. Across the OECD, there is a wide range in this dependency on fossil fuels, from only 15.7 per cent in Iceland through to about 95 per cent in Australia and Ireland. Sweden clearly fares extremely well on this indicator, with a very low level of dependency on fossil fuels (second only to Iceland at 32.7 per cent), whereas Canada falls closer to other OECD countries on this front, with roughly three-quarters ( 74.9 per cent) of its primary energy supply obtained through the burning of fossil fuels. In terms of relative rank, Sweden is second only to Iceland, whereas Canada actually fares slightly better than most (with a rank of 12th overall across 30 countries).

While fossil fuel dependency is fundamental to understanding why Sweden's per capita carbon footprint is so much lower than Canada's (i.e., at the most basic level, Sweden is not nearly as reliant on fossil fuels), it does not explain why Canada's carbon footprint is so high relative to elsewhere in the OECD. With regard to fossil fuel use, Canada is actually quite close to the OECD European average (76.0 per cent), and in fact lower than its North American neighbours (in particular, its dependency is lower than that of its major trading partner, the United States, which ranks 20th overall, with 84.1 per cent of its energy supply derived from either oil, coal, or natural gas). Sweden (along with Iceland) are clearly the outliers on this component, whereas Canada is much closer to where other OECD countries cluster; for example, only 8 of the 30 OECD countries as listed in Table 1 fall below 70 per cent on this index. As will be discussed below, Canada has actually invested more than most in the development of both hydroelectricity and nuclear energy in meeting its domestic needs.

In terms of the second technology term, the carbon intensity effect, Canada is no worse than most OECD countries (ranks 10th), which is not only lower than the OECD average but also slightly lower than Sweden (ranks 13th). While Canada does use coal, primarily in the generation of electricity, it is not nearly as reliant on this energy source as other countries (as for example, only 16 per cent of Canada's electricity comes from burning coal, compared to 45 per cent in the United States and about 75 per cent in Australia). As a ratio of $\mathrm{CO}_{2}$ emissions to total fossil fuel combustion, Canada's 2.735 $\mathrm{Mt} \mathrm{CO}_{2}$ per Mtoe of energy is lower than the OECD's average of 2.837-just as Sweden's carbon intensity is also slightly better than this average, at $2.805 \mathrm{Mt}$ of $\mathrm{CO}_{2}$ per Mtoe of energy consumed. A large proportion of the fossil fuels consumed in Sweden is used in the transportation sector of the economy (oil and diesel), whereas Canadians use fossil fuels for a wider variety of purposes, both in terms of generating electricity, household consumption, and the widespread use of natural gas in 
heating homes as well as industrial and commercial applications. In trying to explain why Sweden's carbon footprint is so much lower than Canada's, the carbon intensity effect, in isolation, does not appear to be particularly important.

With regard to the third technology component-namely, the conversion efficiency effect-Canada's 7th-place ranking is again better than most: its ratio of primary energy supply to final consumption (1.31) is lower than that observed in Europe (1.42), for the OECD overall (1.46), or Sweden (1.42), although the differences observed are not large. Sweden is near the middle of the pack in the OECD, with a slightly lower ratio of primary energy supply relative to final energy consumed. Sweden does not perform as well on this indicator as does Canada (15th v. 7th overall)—although the consequences in terms of $\mathrm{CO}_{2}$ emissions are not great, relating back to the simple fact that Sweden overall burns much less fossil fuel relative to most countries. This ratio is slightly higher in Sweden, given its reliance upon certain non-conventional energy sources, such as the burning of peat and biomass (including wastes from agriculture, their forests, and forest industries). Interestingly, across all OECD countries, Iceland actually ranks the highest on this component (30th overall), given the conversion effect associated with geothermal energy, which has, in turn, a negligible environmental impact. In contrast, the consequences in terms of $\mathrm{CO}_{2}$ emissions and environmental impact are most serious in those countries that continue to rely heavily on fossil fuels, often with rather inefficient and dirty conversion technologies (consider the many coal-fired power plants in Central and Eastern Europe for generating electricity).

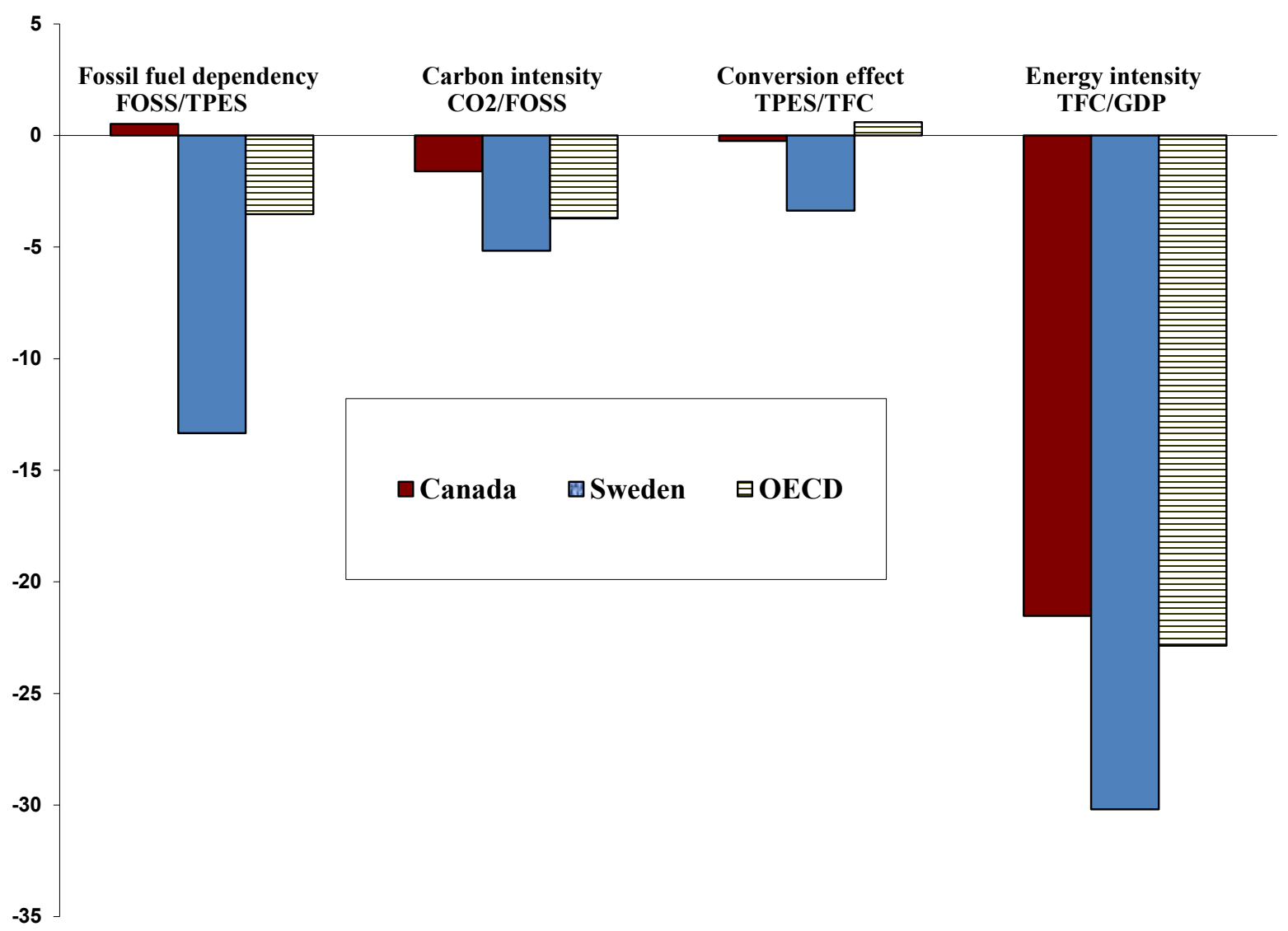

Figure 6. Percentage change in the technology components (1990-2009) for Canada, Sweden, and the OECD Total.

Source: Author's calculations. 
Kerr: Population growth, energy use, and environmental impact

While Canada's record does not depart significantly from most other OECD countries on the first three technology terms, it is with the 4th term - the energy intensity effect - that Canada's performance differs most dramatically (ranks 29th across 30 OECD countries). This fourth technology term simply represents total final energy consumption relative to the total size of a given economy, and here the Canadian ratio is substantially higher than the OECD average (166.73 Mtoe/\$US billion v. 99.62). Whereas Sweden is clearly an outlier with regard to the first technology component (i.e., ranked $2^{\text {nd }}$, with a much lower environmental impact due to low fossil fuel dependency), Canada is clearly an opposite outlier on this fourth term (i.e., ranked 29th, with a higher environmental impact due to the high level of energy consumed).

A country's performance in terms of energy intensity reflects both investments in energy efficiency as well as the nature of its economic activity and its economic structure. Both Canada and Sweden have resource-based economies that are highly export-oriented (Canada to the US and Sweden to other parts of Europe). By both OECD and global standards, Canada's energy use is very high - a simple observation which we shall return to in the concluding discussion and summary. Yet, Sweden also uses considerable energy to drive its economy, but without the comparable environmental impact (ranks $22^{\text {nd }}$ with $106.53 \mathrm{Mtoe} /$ SUS billion). On this index, Sweden is actually closer to the United States (115.75 Mtoe/\$US billion) than it is to most other European countries (OECD Europe reports an average of 84.24 Mtoe/\$US billion).

The simple fact that Sweden has managed to move away from fossil fuels, whereas Canada has not, is a large part of why the two countries are almost at opposite extremes in terms of per-capita $\mathrm{CO}_{2}$ emissions. In demonstrating this simple fact, it is useful to consider the same four technology components, but shifting our emphasis to the change as observed over the 1990-2009 period. Thus, Figure 6 returns to these technology terms, yet this time presenting percentage change for Canada and Sweden separately, relative to what has been observed for the OECD overall. Briefly, in considering all four technology terms, it is striking how Sweden has managed to reduce environmental impact, whereas Canada has lagged behind.

Overall emissions are down in Sweden, despite both population and economic growth. This achievement can be explained by a reduction across all four technology components-fossil fuel dependency ( -13.3 per cent), carbon intensity of fossil fuels used ( -5.2 per cent), losses through energy conversion ( -3.4 per cent), and energy intensity of economic activity ( -30.2 per cent). Meanwhile, Canada also made gains across 3 of the 4 technology terms, but much less so than either Sweden or the OECD in general — carbon intensity down slightly ( -1.6 per cent), negligible change in conversion effect ( -0.2 per cent), and a decline in energy intensity ( -21.5 per cent $)$ and with fossil fuel dependency up slightly (+0.5 per cent). Systematically, for all four technology indicators, Sweden's performance has been superior to Canada's, just as the Sweden experience compares favourably with the rest of the OECD. Canada, on the other hand, has lagged behind not only Sweden but also the OECD average, with the sole exception of its conversion effect, whereas the OECD overall witnessed a very small increase $(+0.598)$.

\section{Discussion}

In explaining Canada's high carbon footprint, of fundamental importance is the simple reality that Canada is a resource-rich country with major reserves of fossil fuels - a situation that it shares with its North American neighbours, the United States and Mexico. This has arguably left it "without" the same sorts of incentives to move away from fossil fuels as are observed elsewhere. Indeed 
Canada is a resource-rich country, with major reserves of coal, natural gas, and oil (including both conventional and oil sands reserves), but it is certainly far from fully exploiting these resources. Much of the existing production of fossil fuels is currently generated for export, with net exports currently equivalent to roughly one-tenth, one-third, and two-thirds of total domestic production of coal, crude oil, and natural gas, respectively.

Governments and industry in Canada continue to encourage growth in the Canadian energy sector, with investments producing an expanding supply of fossil fuels for both domestic consumption and export. Of particular importance in Canada have been the ongoing efforts to expand access to major reserves of bitumen in western Canada (oil sands), with total production from that source already reaching 47 per cent of total Canadian petroleum production in 2007 (Government of Alberta 2008). Oil sands extraction is more environmentally damaging than conventional crude oil extraction, with much higher energy demands and significant water requirements in moving from the well-to-pump. Moreover, fossil fuels are used in extracting and upgrading bitumen reserves into synthetic crude, with roughly one barrel of oil-equivalent of energy required to produce 5-6 barrels of oil for the market (NEB 2006). Canada's willingness to satisfy burgeoning North American energy demands (as now the largest exporter of crude oil to the United States) has only added to the energy intensity of Canadian industry, and compromised the country's ability to meet its climate change commitments. As summarized by Harper and Fletcher (2011), Canada has few regulatory limits on fossil fuel consumption and emissions in those sectors that are in fact the most responsible for GHG emissions - including transportation (25 per cent), fossil fuel development (19 per cent), electricity generation (17 per cent), and industrial activities (15 per cent).

Of importance in the Canadian context has been the implementation of the North American Free Trade Agreement (NAFTA), which has had a dramatic impact on the Canadian economy. Canada has become increasingly a part of the continental energy market, with high levels of foreign ownership and constrained governmental policy flexibility. On a deeper level, in both Canada and the United States, energy use remains very high, in an energy policy context of relatively low taxes (in contrast to OECD Europe) and low energy prices. ${ }^{3}$ In the North American context, lower taxes on energy (relative to elsewhere in the OECD) are responsible for relatively low prices for both consumers and industry, which have arguably undercut some of the potential for conservation, with fewer incentives to increase efficiencies. In addition to fossil fuel, Canada's export-oriented economy is particularly energy intensive, as it produces far more than its population would suggest. In fact, Canada currently produces over 10 per cent of the world supply of aluminum, 5 per cent of the copper, 9 per cent of gypsum, 12 per cent of nickel, 15 per cent of wood pulp, 23 per cent of newsprint, and about 30 per cent of the world's supply of potash fertilizers - all for a country that has less than 0.5 per cent of the global population (Environment Canada 2006). As all of these industries are particularly energy intensive, production of these commodities contributes significantly to Canada's overall high demand for energy.

3. The IEA (2011) produces summary statistics on the cost of energy, allowing for systematic comparisons across the OECD. In drawing international comparisons, the price of gasoline has been lower in Canada than in any other OECD country (with the exception of the United States and Mexico) for well over a decade. Similarly, Canadian electricity prices have consistently been second-lowest, only above Norway, while the price of natural gas demanded of Canadian households and industry has consistently been second-lowest, only above Finland. In reviewing IEA data, countries with higher prices—which clearly would include Swedenalso tend to consume less, an observation often raised by environmentalists in advocating carbon taxes in order to reduce environmental impact. 
Kerr: Population growth, energy use, and environmental impact

Sweden is in a very different situation in terms of energy resources, i.e., it has long been reliant upon others in meeting its demand for oil and natural gas. As it is almost completely reliant on imports in meeting this demand, in response to scarcity, it has developed alternatives. Benefiting from a geography and topography that allowed for it, Sweden first produced hydroelectricity in a major way during the early 20th century, and since the 1970s, it has had nuclear energy, as well. In combination, these two energy sources provide for almost 90 per cent of Sweden's electricity supply, with the remainder produced by burning fossil fuels and/or other non-conventional energy sources, including wind, bio-energy, and — to a very limited extent—solar cells, wave energy, and geothermal. One can only speculate as to how Sweden's record might have differed had it been in a similar situation to Canada, i.e., with major fossil fuel reserves. While it can be credited for being politically committed to reducing its carbon footprint, Sweden's relatively favorable record at least partially relates to the necessity of seeking out alternatives to fossil fuels in the absence of a domestic supply.

There is little disputing the fact that North Americans use a great deal of energy, and that the typical Canadian uses more energy than the typical Swede (although this difference should not be overstated or exaggerated). The Swedes — and more broadly, the Scandinavians — have the reputation of being more ecologically frugal, with considerable popular support for various types of "green" reform and environmental policy (Hallding et al. 2013). North Americans tend to drive less fuelefficient vehicles, and drive them further; they also live in larger homes and heat them more, and work in buildings that use more energy than do Europeans (Environment Canada 2006). In terms of Canada's particularly heavy energy use, at least part of this situation relates to the simple fact that its climate is among the coldest in the OECD, requiring far more heating days than most other countries. Yet this is a situation that it shares with Sweden, among other northern Scandinavian countries. While average winter temperatures are roughly the same in Toronto and Stockholm, Sweden has been innovative in reducing its demand for energy, with major infrastructure investments in district heating and heat co-generation. Sweden also faces lower energy demands than Canada in terms of transportation, with a smaller landmass and greater population densities (towards the south of the country), and with major investments in both public transit and rail. Canada is a particularly large country (second in the world to only Russia), which in combination with low overall population density serves to increase the costs and energy required in transportation. The distances travelled in Canada in moving both freight and people tends to surpass those observed in most (much smaller) European countries, including Sweden (MKJA 2005). In turn, the transportation sector, both personal and freight, is responsible for a large proportion of Canada's energy use-reported at roughly 29 per cent of total secondary energy use in 2007 (NRC 2010). In Sweden, the comparable figure for transportation is roughly 24 per cent (European Commission 2007).

Canada uses more energy (per unit of GDP) than practically any other country in the OECD; as of 2009 , Iceland is the only country with a higher energy intensity. In many respects, it is Iceland rather than Sweden that is the most atypical country in the OECD—-this small North Atlantic country that hovers around the Arctic Circle has managed to navigate into the 21 st century with an economy that is even more energy-intensive than Canada (30th in the OECD), while simultaneously having a modest environmental impact. As was the case with Sweden, Iceland is atypical in terms of the (T) component in IPAT; more specifically, its reported fossil fuel dependency is very low. In addition, Iceland is located along the mid-Atlantic ridge in a highly geologically and volcanically active location, and thus has managed to exploit an abundance of geothermal energy, using technologies that tap into this primary energy source with negligible environmental effect. The crux of the matter for Iceland is its abundant, almost unlimited amount of geothermal energy. On the other hand, the 
crux of the matter for Sweden is its shift away from fossil fuels through the development of both nuclear and "hydro" electricity. And the crux of the matter for Canada is that it continues to rely on fossil fuels in a context of high energy use. While all three societies have relatively high demands in terms of energy (true by both OECD and world standards), in a predictable manner, it is Canada that has a particularly poor record on $\mathrm{CO}_{2}$ emissions (both overall and on a per-capita basis).

While Sweden's economy uses less energy than Canada's, its energy intensity is actually, somewhat surprisingly, greater than most OECD countries (as aforementioned, Sweden's rank of 22nd is actually not too far from Canada's rank of 29th overall). The Swedish economy also has an important resource sector that uses heavy energy input in the production of timber, mining, and iron ore, among many other basic commodities. Moreover, Sweden's manufacturing sector is relatively important-although, like in Canada, the overall proportion of Swedes employed in this sector has been steadily declining. In terms of overall energy use, Sweden's energy intensity (106.63 Mtoe/\$US billion) is actually higher than the OECD average (99.62 Mtoe/\$US billion), and substantially higher than OECD average for Europe (84.24 Mtoe/\$US billion).

In suggesting the importance of the technology component, Sweden's energy intensity is nearly identical to Luxembourg's (106.84 Mtoe/\$US billion), a country which is actually the OECD's worst performer in terms of $\mathrm{CO}_{2}$, with per-capita emissions that are more than 4 times the levels recorded in Sweden. While Sweden has been at the forefront in terms of environmental initiatives and eco-innovation, it would be a misrepresentation to indicate that its environmental impact is low due to low energy consumption. While there are clearly important differences in political culture across OECD countries, including greater support for environmental initiatives in Sweden than elsewhere, it would be somewhat simplistic to try to explain the differences in overall $\mathrm{CO}_{2}$ emissions exclusively through individual consumption patterns and lifestyle choices. More basic in this context are observed differences in economic structure, along with some rather dramatic differences in terms of "energy supply." When comparing Canada with Sweden, consumption patterns are not that dramatically different (consumers in both countries have a very high standard of living by both OECD and global standards, as maintained by a high demand for energy). Yet Canada's exports are more energy-intensive than are Sweden's, while it continues to heavily rely on fossil fuels in driving its economy.

There are certainly other economic and political factors, not easily operationalized in the context of the current decomposition, that should be at least briefly raised in this attempt to explain the differences observed between Canada and Sweden. In particular, when it comes to explaining recent trends in $\mathrm{CO}_{2}$ emissions, it is useful to highlight a few concurrent economic trends-including the increased globalization of trade, with the corresponding interconnectedness of national economies and peoples. With the decline in manufacturing across many western economies, other economies (e.g., China, India, Brazil) have corresponding increased economic activity in the production of these same manufactured goods. This shift in the location of manufacturing has been driven by a wide assortment of factors, including the cost of labor, without a comparable shift in terms of where these same goods are consumed. As China has recently surpassed the United States as the world's largest emitter of $\mathrm{CO}_{2}$, it is difficult to ignore the simple fact that much of what is produced in China is produced for export. Thus, the increased interconnectedness of the world economy further complicates any analysis of consumption and environmental impact.

As Davis and Caldeira (2010: 5,687) point out, "much attention has been focused on the $\mathrm{CO}_{2}$ directly emitted by each country" (i.e., what is referred to as production based inventories), which in fact has been the primary emphasis of the current paper, in the application of the IPAT accounting framework. This is also the convention followed by most international organizations concerned with 
Kerr: Population growth, energy use, and environmental impact

charting recent trends in energy use and $\mathrm{CO}_{2}$ emissions. For example, national inventories are published annually by parties subject to the UN Framework Convention on Climate Change, in order to document the progress (or lack thereof) of member states in meeting international commitments. Alternatively, it is pointed out that "relatively little attention has been paid to the amount of emissions associated with the consumption of goods and services in each country, regardless of where the goods might have been produced"- that is, a consumption-based accounting of $\mathrm{CO}_{2}$ emissions. This is considered important, as the record of many countries is blemished to a certain extent when looking beyond the $\mathrm{CO}_{2}$ produced within their borders to that which is generated elsewhere in the production of goods that are eventually consumed domestically through imports.

Davis and Caldeira documented that while the Swedes can be credited for their commitment toward reducing $\mathrm{CO}_{2}$ emissions within their boundaries, a substantial proportion of what is consumed in Sweden is actually produced elsewhere, with substantial $\mathrm{CO}_{2}$ emissions associated with these imports. Davis and Caldeira have estimated that Sweden, like much of Western Europe, is clearly a "net importer" of $\mathrm{CO}_{2}$, whereas Canada is a modest "net exporter." Briefly, some countries (like Canada) can be thought of as "net exporters of $\mathrm{CO}_{2}$ ", as they produce more emissions in the extraction and production of goods for export than they do indirectly through the consumption of goods produced elsewhere (emissions embodied in imports). Other countries (like Sweden) can be thought of as "net importers of $\mathrm{CO}_{2}$," as they produce fewer emissions in the production of goods for export than they do in the consumption of goods produced abroad yet consumed domestically.

More specifically, Davis and Caldeira estimate that Sweden is responsible for almost as much $\mathrm{CO}_{2}$ produced outside of its border in meeting its national needs as it actually produces within its borders, i.e., roughly 40 per cent of all the emissions associated with Swedish consumption are associated with "net imports." While Canada likewise imports $\mathrm{CO}_{2}$ emissions, its exports an even larger amount - such that about 5 per cent of its total emissions are associated with "net exports." As a result, roughly one-half of the original discrepancy between Canada and Sweden disappears when we shift from the current production-based accounting of $\mathrm{CO}_{2}$ to the alternative consumption-based accounting framework. In a sense, it is not that Canada's record is so much better when we consider the impact of international trade (i.e., per capita emissions are only reduced modestly), but alternatively, that the emissions associated with most of the OECD look that much worse.

\section{Conclusion}

We have applied the IPAT model to both Sweden and Canada, in an effort to better understand some of those factors most responsible for their divergent records on $\mathrm{CO}_{2}$ emissions. As aforementioned, total $\mathrm{CO}_{2}$ emissions produced in Canada have risen by roughly +20 per cent over the 1990-2009 period, whereas Swedish emissions have declined by roughly the same percentage ( -21 per cent). Sweden's success in this context clearly relates to the progress it has made in terms of reducing environmental impact across all four technology terms defined above, i.e., it has reduced its fossil fuel dependency, carbon intensity, conversion losses, and energy intensity. On the other hand, Canadian emissions have continued to rise, in the context of rapid demographic and economic growth, without the same sort of success on these same technology terms.

Canada's population continues to grow at a relatively robust pace, up by 21.6 per cent over the 1990-2009. Sweden has not experienced nearly the same sort of demographic pressure, with its population up by 8.8 per cent over this same period. In a general sense, Canadian society is committed to continued demographic growth, with wide popular support for current immigration and 
multicultural policy. While Sweden also relies upon immigration in maintaining its population, it does not receive nearly as many immigrants as Canada, as is the case with much of Western Europe. The question that was been raised in the context of the current paper is "to what extent the Canadian and Swedish records on $\mathrm{CO}_{2}$ emissions have differed as a result of demography"? While admittedly the impact of population growth on $\mathrm{CO}_{2}$ emissions is not necessarily straight forward, there is little disputing the simple fact that increased population implies increased consumption, with a corresponding environmental impact.

The obvious by-product of this demographic reality is that Canada must achieve greater reductions in per capita emissions in efforts to achieve its international commitments whereas Sweden does not have the same sorts of demographic pressures. In a sense, GHG emissions as associated with specific source countries (i.e. countries witnessing much emigration) are shifted to their respective countries of destination (countries witnessing much immigration). Population growth, as increasingly driven by the movement of peoples across international borders, is relevant in explaining why some countries in the OECD have had greater success than others in meeting international commitments. Yet the net impact on global emissions is much the same, unless levels and patterns of consumption change dramatically after migration from one country to the next.

The OECD (2002) has used the term "decoupling" to refer to the breaking of the link between "environmental bads" and "economic goods". Typically, while population, economic growth and environmental impact tend to increase together, a few OECD countries, including Sweden, appear to have at least partially "decoupled" economic growth from $\mathrm{CO}_{2}$ emissions. As portrayed in the current paper, most countries in the OECD have experienced considerable economic growth over the 1990-2009 period, and more specifically, GDP per capita has gone up considerably (for example, by +27.9 per cent and +31.1 per cent in Canada and Sweden, respectively). Yet while the Swedes can be credited for their ability to reduce $\mathrm{CO}_{2}$ emissions in this context, there are certainly complicating factors that blemish its environmental record. By ignoring the "consumption based" accounting of $\mathrm{CO}_{2}$ emissions, the impact of climbing affluence (A) in specific countries can be misstated to an uncertain extent, i.e. there is considerable evidence to suggest that it is understated in the context of Sweden, and conversely, modestly overstated in Canada.

Globalization involves the continued expansion of international trade, through reduction of barriers and restrictions on the movement of capital and on investment. In this context, the Swedish government has recently committed itself to be completely "oil-free" by the year 2020 (PMO Commission 2006). At least partially due to the political climate in Sweden and the relative success of the environmental movement, Sweden has restated its commitment toward reducing its dependency on fossil fuels In direct contrast, the Canadian government is actively encouraging investment and export of crude oil to the United States, among other commodities. Even further, the Canadian government is promoting a diversification of markets for its oil beyond the United States, as for example, it is now actively promoting the construction of a major pipeline to the Pacific coast - with direct targeting of China, among other Asian markets. In an obvious manner, Canada now seems positioned to become an even greater exporter of $\mathrm{CO}_{2}$ emissions. There is little disputing the fact that Canada and Sweden appear to be moving in opposite directions - one toward a low carbon future (within its own borders), while the other shows no hesitancy in meeting an insatiable international appetite for fossil fuels. In this context, the IEA forecasts continued economic growth throughout the OECD, with a continued increase in the demand for energy.

While most countries in the OECD have managed to reduce the energy intensity of their economies (a situation which is also true of Canada), economic and demographic growth has typically 
Kerr: Population growth, energy use, and environmental impact

more than not offset the progress made on this front. This has been particularly true when little progress is made in terms of reducing the carbon intensity and/or fossil fuel dependency of our economies. This has been true of Canada, as it has been true of a majority of OECD countries (fully 19 out of 30 experienced an increase in overall emissions over the 1990-2009 period). While the energy intensity of Canada's economy declined somewhat, it actually lagged behind most OECD countries on this front, and remains one of the most energy intense economies in the world. As the Canadian geographer, Vaclav Smil (2010:149) has recently highlighted in reviewing the many myths and realities of energy use, both in Canada and internationally:

A world without fossil fuel combustion is highly desirable, and, to be optimistic, our collective determination, commitment, and persistence could accelerate its arrival. But getting there will be expensive and will require considerable patience. Coming energy transitions will unfold, as past ones have done, across decades, and not years.

As argued here, the IPAT model is simple, robust and useful as a framework for research, as an elegantly simple way of illustrating different but related dimensions of environmental impact: as functions of the number of people, the technologies they employ to produce goods, and the amount of goods they consume. While the emphasis on a production-based inventory has its problems, the analysis does provide insight as to how different OECD countries have performed in terms of $\mathrm{CO}_{2}$ emissions over recent years. Yet there are certainly limits to the IPAT equation, as for example, this model constrains a priori the effects of each component to be proportional. With this in mind, there have been important revisions of IPAT, as for example, Dietz and Rosa (1994) have reformulated this environmental accounting equation into stochastic form, meant to alternatively estimate the net effect of specific drivers, while also holding the potential for inclusion of theoretically relevant variables including political, social and cultural factors. While IPAT is particularly useful on a descriptive level, there are analytically complex models that hold considerable promise in terms of nomothetic explanation. York et al. (2003a, 2003b) have provided a particularly useful overview of some of the options available in this regard, in terms of analysis and hypothesis testing, in efforts to more precisely specify the sensitivity of environmental impacts to the forces driving them. Jorgenson (2003) has used SEM in an effort to model other potential drivers of environmental impact, including urbanization, adult literacy, domestic inequality, among other political and economic factors. Davis and Caldeira's (2010) emphasis on consumption over production in the accounting of $\mathrm{CO}_{2}$ hints at the potential for further methodological innovations in disentangling the complex relationship between population and environment, all in a context of globalization.

\section{References}

Boyd, D. 2001. Canada vs the OECD: An Environmental Comparison. Eco-Research Chair of Environmental Policy. Victoria BC: University of Victoria.

Chertow, M. 2001. The IPAT equation and its variants: Changing views of technology and environmental impact. Journal of Industrial Ecology 4(4):13-29.

Clapp, J. 2002. The distancing of waste: Overconsumption in a global economy, in Confronting Consumption, edited by T. Princen and K. Conca. Cambridge MA: M.I.T. Press, pp. 155-176.

Commoner, B., M. Corr, and P. Stamler. 1971. The causes of pollution. Environment 13(3):2-19. 
Davis, S.J., and K. Caldeira. 2010. Consumption based accounting of $\mathrm{CO}_{2}$ emissions. Proceedings of the National Academy of Sciences in the United States 107:5687-5692.

Dietz, T., and E. Rosa. 1994. Effects of population and affluence on $\mathrm{CO}_{2}$ emissions. Proceedings of the National Academy of Sciences 94(1):175-179.

Ehrlich, P.R., and J. Holdren. 1971. Impact of population growth. Science 171(3977):1212-1217. 1972. One-dimensional ecology. Bulletin of the Atomic Scientists 28:16-27.

Environment Canada. 2006. Canada's Fourth National Report on Climate Change: Actions to Meet Commitments Under the United Nations Framework Convention on Climate Change. Ottawa: Environment Canada.

- 2011. National Inventory Report, 1990-2009: Greenhouse Gas Sources and Sinks in Canada. Catalogue No. En81-4//1-2009E.

European Commission. 2007. Swedish - Energy Mix Fact Sheet.

Government of Alberta. 2008. Alberta's Oil Sands: Opportunities, Balance. Edmonton, AB: Government of Alberta.

Hallding, K., E.A. Eriksson, M. Mobjörk, M. Nilsson, E. Alfredsson, K. Skånberg, H. Sonnsjö, M. Benzie, H. Carlsen, and E. Kemp-Benedict. 2013. Sweden in a World of Growing Uncertainties: Background Report 10 to the Commission on the Future of Sweden. Stockholm: Stockholm Environment Institute.

Hamilton, C., and H. Turton. 2002. Determinants of emissions growth in OECD countries. Energy Policy 30:63-71.

Harper, C.L., and F. Fletcher. 2011. Environment and Society: Human Perspectives on Environmental Issues. Canadian Edition. Toronto: Pearson Canada.

IEA. 2011. Data Services, International Energy Association. http://www.iea.org/stats/ . Cited July 3, 2011. http://www.iea.org/stats/ .

IPCC. 1996. Intergovernmental Panel on Climate Change, Second Assessment. Cambridge (UK): Cambridge University Press.

2000. Intergovernmental Panel on Climate Change: Summary for Policymakers. Cambridge (UK): Cambridge University Press.

Jorgenson, A. 2003. Consumption and environmental degradation: A cross-national analysis of the ecological footprint. Social Problems 30(3):371-394.

Karakaya, E., and M. Ozcag. 2005. Driving forces of $\mathrm{CO}_{2}$ emissions in Central Asia: A decomposition analysis of air pollution from fossil fuel combustion. Arid Ecosystems Journal 11(26):49-57.

Kaya, Y. 1990. Impact of carbon dioxide emission control on GNP growth: Interpretation of proposed scenarios. Paper presented to the IPCC Energy and Industry Subgroup, Response Strategies Working Group, Paris.

Kerr, D., and H. Mellon. 2012. Energy, population and the environment: Exploring Canada's record on $\mathrm{CO}_{2}$ emissions and energy use relative to other OECD countries. Population and Environment 34:257278.

MKJA. 2005. Technical Report: National Circumstances Affecting Canada’s Greenhouse Gas Emissions. Duplicate. 
Kerr: Population growth, energy use, and environmental impact

NEB (National Energy Board). 2006 Canada's Oil Sands, Opportunities and Challenges to 2015: An Update. Catalogue No. NE23-116/2006E.

NRC. 2010. Energy Efficiency Trends in Canada. Ottawa: Natural Resources Canada, Office of Energy Efficiency.

OECD. 2002. Indicators to Measure Decoupling of Environmental Pressure from Economic Growth. The OECD Environmental Programme, Paris.

—. 2011. OECD Statextracts: GDP constant US\$ PPP adjusted. Cited July 3, 2011.

PMO Commission. (Prime Minister's Office Commission on Oil Independence). 2006. Making Sweden an Oil Free Society. Stockholm.

Rees, W. 1992. Ecological footprints and appropriated carrying capacity: What urban economics leaves out. Environment and Urbanization 4(2):121-130.

Simon, J. 1981. The Ultimate Resource. Princeton NJ: Princeton University Press.

Simpson, J., M. Jaccard, and N. Rivers, 2007. Hot Air: Meeting Canada's Climate Change Challenge. Toronto: McClelland and Stewart Ltd.

Smil, V. 2010. Energy Myth and Realities: Bringing Science to the Energy Policy Debate. Washington: AEI American Enterprise Institute.

SEPA (Swedish Environmental Protection Agency). 2011. Informative Inventory Report, 2011.

Statistics Canda. 2010. Population Projections for Canada, Provinces and Territories, 2009 to 2036. Catalogue No. 91-520-X.

UN (United Nations). 2011a. Population Data On-line. Department of Economic and Social Affairs. UN Population Division. Population Estimates and Projections Section.

—. 2011b. Human Development Report. United Nations Development Program.

York, R., E. Rosa, and T. Dietz. 2003a. Footprints on the Earth: The environmental consequences of modernity. American Sociological Review 68(2):279-300.

2003b. STIRPAT, IPAT and ImPACT: Analytic tools for unpacking the driving forces of environmental impacts. Ecological Economics 46:351-365. 